\title{
Optical Properties of Paper and Polyethylene Mulches Used for Weed Control in Lettuce
}

\author{
D. Brault ${ }^{1}$ and K.A. Stewart ${ }^{2}$ \\ Department of Plant Science, Macdonald Campus of McGill University, \\ Ste-Anne-de-Bellevue, Québec, Canada, H9X 3V9
}

\section{S. Jenni ${ }^{3}$ \\ Horticultural Research and Development Centre, Agriculture and Agri-Food Canada, St-Jean-sur-Richelieu, Québec, Canada, J3B 3E6}

Additional index words. Lactuca sativa, organic soil, plastic mulch, mulch decomposition, light transmission, light reflection, Cyperus esculentus

\begin{abstract}
Optical properties of paper and plastic mulches were determined in experiments on mulched head lettuce (Lactuca sativa L.) grown in organic soil in 1997-98. Mulches used in 1997 were a coextruded white/black polyethylene, a beige paper coated with latex on both sides and a black paper coated with latex on both sides. Three supplementary mulches were added in the 1998 experiment: beige paper coated with a biodegradable polymer either coated on the underside, on the top side or on both sides. Optical properties of the polyethylene mulch remained stable over the course of the experiment. As the paper mulches aged, they changed structurally, spectrally, or both, but remained in place until harvest. The black paper was the only mulch that offered complete weed control, although the weeds under the other mulches did not develop beyond the cotyledonary or two-trueleaf stage.
\end{abstract}

Three aspects of weed control create major economic constraints in lettuce production. First, weed control is an expensive, timeconsuming operation. In the United States, hand hoeing can account for $35 \%$ to $40 \%$ of a grower's preharvest production costs (Naegely and Greenleaf, 1999). In Quebec, head lettuce growers control weeds by applying a preemergence herbicide coupled with manual and mechanical weeding throughout the season. This last operation can cause injuries to the root system and reduce both yield and quality (Roberts et al., 1977; Shrefler et al., 1996). Finally, standard weed control methods can be phytotoxic to the crop and are not always effective. For example, a number of Quebec lettuce fields have been abandoned or allocated to different crops because of yellow nutsedge (Cyperus esculentus L.) infestation. Yellow nutsedge is very difficult to control, as a single tuber may, within one year, give rise

Received for publication 16 Aug. 2000. Accepted for publication 3 May 2001. Agr. and Agri-Food Can., Saint-Jean-sur-Richelieu (Qué), Contribution no. 335/2001.03.03R. This paper is a portion of a MS thesis submitted by D. Brault. We thank the technicians for their assistance. Mention of trade name or specific equipment does not constitute a guarantee, warranty or endorsement of the product. This project was supported by a grant from the Matching Investment Initiative (MII) of Agriculture and Agri-Food Canada in collaboration with Cascades Multi-Pro and Innotag. D. Brault was supported by a Fellowship from the Fonds pour la formation de Chercheurs et l'Aide à la Recherche (FCAR).

${ }^{1}$ Graduate Student.

${ }^{2}$ Associate Professor.

${ }^{3}$ Research Plant Physiologist. mine the weed control effectiveness of a coextruded white/black polyethylene mulch and various types of paper mulches (color and coating) in the production of head lettuce.

\section{Materials and Methods}

Location. This experiment was conducted during the summers of 1997 and 1998 in Sherrington, Quebec (lat. $45^{\circ} 10^{\prime} \mathrm{N}$; long. $73^{\circ} 31^{\prime} \mathrm{W}$ ), and in Napierville, Quebec (lat. $45^{\circ} 11^{\prime} \mathrm{N}$; long. $73^{\circ} 25^{\prime} \mathrm{W}$ ), respectively. The lettuce seedlings were planted in a well decomposed organic soil (humisol) in commercial lettuce fields. Barley and turf crops preceded the 1997 and 1998 plantings, respectively. No herbicide was used.

Experimental layout. Mulches used during the experiment in 1997 were a coextruded white/black polyethylene, a beige paper coated on both sides with latex, and a black paper coated on both sides with latex (Table 1). Three mulch treatments were added to the experiment in 1998. They were beige paper coated with a biodegradable polymer on the underside, on the topside, or on both sides. Mulch treatments were compared with weeded and nonweeded controls. Treatments were replicated four times in a randomized complete-block design. Mulches were laid by hand 9 July and 3 June in 1997 and 1998, respectively. One day after the mulches were laid, lettuce plants cv. Ithaca ( $29 \mathrm{~d}$ and $25 \mathrm{~d}$ old in 1997 and 1998, respectively) were transplanted in 3.2-cm-wide holes on raised beds $0.15 \mathrm{~m}$ high and $0.76 \mathrm{~m}$ wide. Plots were $10.26 \mathrm{~m}$ long in 1997 and $12.7 \mathrm{~m}$ long in 1998. Plants were staggered in adjacent rows with $35.6 \mathrm{~cm}$ within and $44.5 \mathrm{~cm}$ between rows. Beds and blocks were spaced $1.27 \mathrm{~m}$ and $1.0 \mathrm{~m}$ apart, respectively. A section of $4.27 \mathrm{~m}$ in each plot was used for weed counts and spectroradiometric measurements. Plots were sprinkler irrigated immediately pre-and postplanting following the standard practice for the region.

Mulch decompositionmeasurements. Degradation measurements were undertaken in 1998. Degradation was evaluated weekly by measuring the percentage of degradation at the mulch air/soil interface. Degradation below the soil surface or under the lettuce leaves near the end of the experiment was not taken into account.

Table 1. Mulch treatments used in 1997-98.

\begin{tabular}{|c|c|c|c|c|c|}
\hline \multirow[b]{3}{*}{$\underline{\text { Material }}$} & \multirow[b]{3}{*}{ Color } & \multirow[b]{3}{*}{ Coating } & \multicolumn{3}{|c|}{ Lettuce plants } \\
\hline & & & \multirow{2}{*}{$\frac{1997}{\text { With }}$} & \multicolumn{2}{|c|}{1998} \\
\hline & & & & With & Without \\
\hline \multicolumn{6}{|c|}{ Mulched treatments } \\
\hline Polyethylene $^{z}$ & White/Black & & $\mathrm{x}$ & $\mathrm{x}$ & $\mathrm{x}$ \\
\hline Papery $^{y}$ & Black & Latex double-sided & $\mathrm{x}$ & $\mathrm{x}$ & $\mathrm{x}$ \\
\hline Paper & Beige & Latex double-sided & $\mathrm{x}$ & $\mathrm{x}$ & $\mathrm{x}$ \\
\hline Paper & Beige & Biodegradable polymer underside & & $\mathrm{x}$ & $\mathrm{x}$ \\
\hline Paper & Beige & Biodegradable polymer topside & & $\mathrm{x}$ & $\mathrm{x}$ \\
\hline \multirow[t]{2}{*}{ Paper } & Beige & Biodegradable polymer double sided & & $\mathrm{x}$ & $\mathrm{x}$ \\
\hline & & Nonmulched treatments (controls) & & & \\
\hline Nonweeded & & & $\mathrm{x}$ & $\mathrm{x}$ & $\mathrm{x}$ \\
\hline Weeded & & & $\mathrm{x}$ & $\mathrm{x}$ & \\
\hline
\end{tabular}

${ }^{2}$ Coextruded $1.1 \mathrm{~mL}, 137 \mathrm{~cm}$ wide, white topside, supplied by Plastitech Culture, St-Rémi, Québec. 'Kraft paper $83 \mathrm{~g} \cdot \mathrm{m}^{-2}, 122 \mathrm{~cm}$ wide, supplied by Cascades Multi-Pro, Drummondville, Québec. 
Optical property measurements. Weekly, a $25 \times 25-\mathrm{cm}$ mulch sample was cut between the rows of lettuce in the plot. The hole was covered with a soil-filled plastic bag to secure the cut edges and prevent wind from lifting the mulch. The mulch sample was then labelled, cleared of dirt with a small paintbrush, dried at room temperature, sealed in an envelope, and placed in the dark. Subsamples for all mulches were used to analyze their optical properties in laboratory. Reflection and transmission of light were measured in 10-nm increments over the $400-1100 \mathrm{~nm}$ range with a LI-1800 spectroradiometer (LI-COR, Lincoln, Nebr.). Absorption was calculated using the equation $1=$ $a+r+t$, where $a$ is absorption, $r$ is reflection and $t$ is transmission (Rosenberg et al., 1983). Results were an average of four sub-samples per treatment and were quite stable within the treatments.

Weed population measurements. Weekly, weeds with stems within the $25 \times 25$-cm area were counted and the aboveground biomass was evaluated. Weeds were separated into monocotyledonous or dicotyledonous groups and dried at $70{ }^{\circ} \mathrm{C}$ for 24 to $48 \mathrm{~h}$. In 1998 , an additional experiment was undertaken in a nutsedge-infested field in Sherrington, Quebec, to evaluate the effectiveness of the mulches against yellow nutsedge (Cyperus esculentus L.). With the exception of a weeded control, the treatments of the 1998 Napierville experiment with lettuce (Table 1) were repeated for this experiment. Mulches were laid by hand 8 May and removed $61 \mathrm{~d}$ later. Beds were 0.15 $\mathrm{cm}$ high, $1 \mathrm{~m}$ long, and $0.76 \mathrm{~m}$ wide. Treatments were replicated four times in a randomized complete-block design. At the time the mulch was laid, no weeds were visible. No holes were made in the mulch and no crop was cultivated. At the end of the experiment, the mulches were removed and the weeds on the complete bed were harvested. Weeds collected during the experiment were separated into two groups: yellow nutsedge and other weeds. Weeds within each group were counted and the aboveground biomass was dried for a period of $48 \mathrm{~h}$ at a temperature of $70{ }^{\circ} \mathrm{C}$.

Statistical analysis. Results were analyzed statistically using the Statistical Analysis System (SAS Institute, Cary, N.C., 1998). When treatment effects were significant $(P<$ 0.05 ), differences among means were detected using the Student-Newman-Keuls (SNK) test.

\section{Results and Discussion}

Decomposition of the paper mulch in 1998. Degradation along the edges of the paper became visible $21 \mathrm{~d}$ after the mulch was laid (Fig. 1). Degradation of the beige papers coated on either both sides or on the underside with biodegradable polymer was negligible $(<0.1 \%)$ or nil for the duration of the 1998 experiment, whereas the degradation was between $3 \%$ and $5 \%$ for all other papers.

Visible degradation for the paper coated with latex occurred where the edges of the papers were in contact with the soil. Similar results had been found with a black asphalted paper mulch (Hutchins, 1933) and a plain

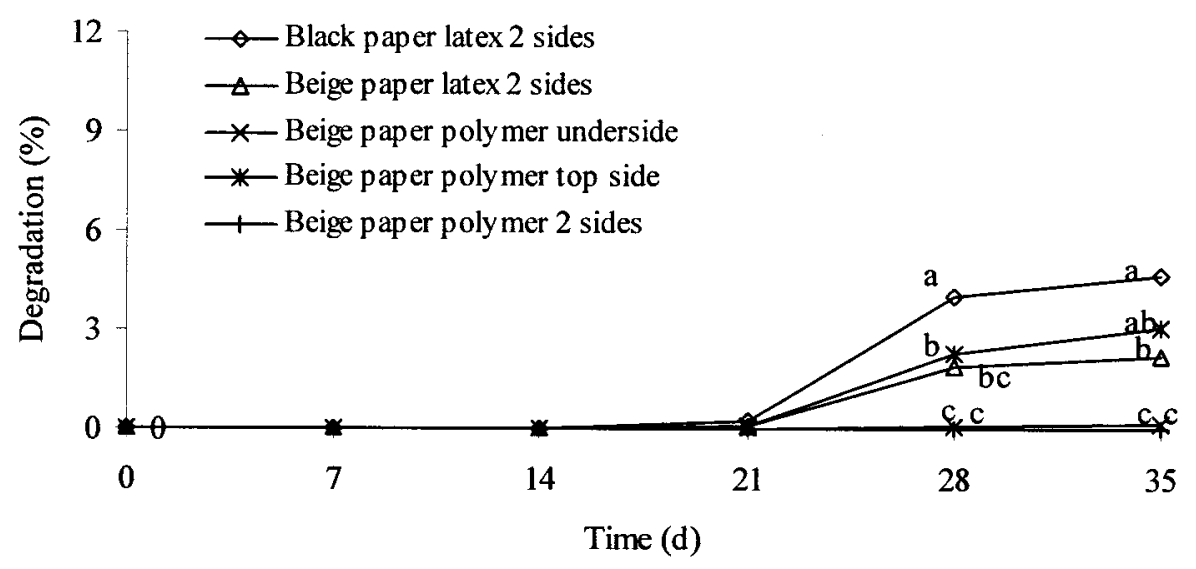

Fig. 1. Percentage of degradation along the mulch air/soil interface $0,7,14,21,28$, and $35 \mathrm{~d}$ after mulch placement in 1998. Mean separation within sampling day using a Student-Newman-Keuls test at $P<$ 0.05 . Results are means for four blocks.
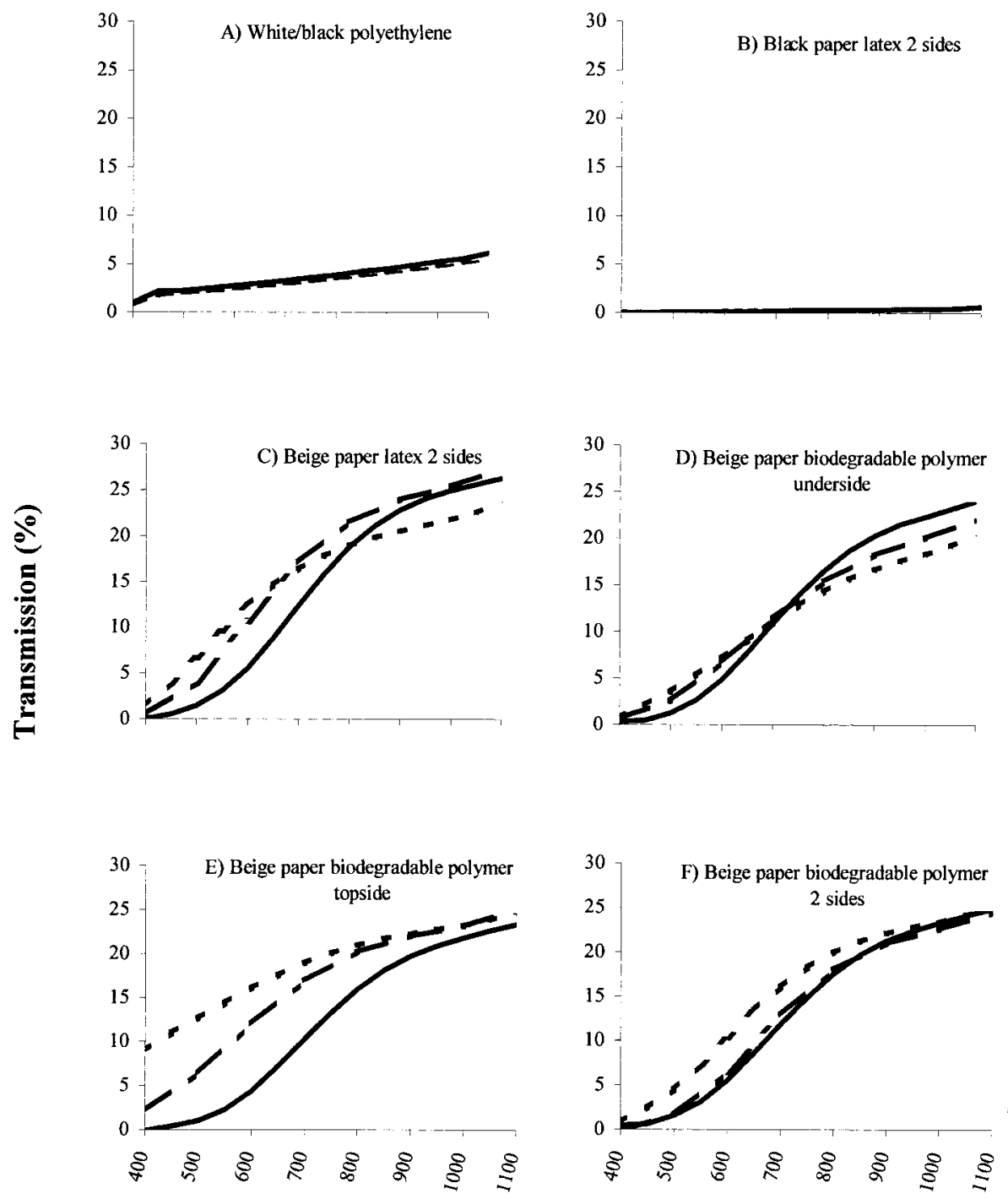

Wavelength (nm)

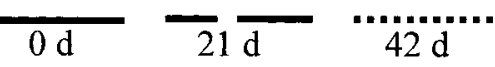

Fig. 2. Percentage of light transmission through polyethylene and paper mulches, after 0,21 , and $42 \mathrm{~d}$ in the field. 
paper mulch (Anderson et al., 1995). Paper decomposition was also observed 2 to $3 \mathrm{~cm}$ below soil level but was not evaluated to avoid manual damage to the mulch.

The biodegradable polymer coating of the paper coated on the topside started to peel away from the paper $14 \mathrm{~d}$ after mulch placement. Once a crack or break appeared on the top surface of the bed, degradation was rapid and complete areas of the paper started to decompose after $21 \mathrm{~d}$ for this mulch (data not shown).

At the end of the experiment, the polyethylene mulch was removed by hand and landfilled, whereas the paper mulches were disc-harrowed into the soil.

Spectroradiometry: Transmission of light. Mulch samples taken 0,21, and $42 \mathrm{~d}$ from the start of the experiment were spectrally analyzed in the laboratory. Minimal light was transmitted through the coextruded white/black mulch (average of $2 \%$ ) and black paper mulch (average of $0.08 \%$ ) (Fig. 2 A and B). Transmission in the infrared (IR) range (775 to 1100 $\mathrm{nm}$ ) was less than $10 \%$ for the coextruded white/black polyethylene mulch and $<1 \%$ for the black paper mulch.

An average $4.3 \%$ of light in the photosynthetically active radiation $(P A R)$ range (400-700 nm) was transmitted through the beige paper mulch coated on both sides with latex (Fig. 2C). This percentage increased over time reaching $9.4 \%$ after $42 \mathrm{~d}$. Light transmission in the near IR range was $>20 \%$ during the first $21 \mathrm{~d}$ of the experiment and decreased slightly at $42 \mathrm{~d}$.

The three papers coated with biodegradable polymer (Fig. 2D-F) had initial light transmission patterns similar to those of the beige paper coated with latex (Fig. 2C). Less than $10 \%$ of the light was transmitted in the $P A R$ range at the beginning of the experiment. Light transmission in the $P A R$ region through the paper treated with polymer on the topside was $>10 \%$ after $42 \mathrm{~d}$ (Fig. 2E). Paper treated with either the polymer on the underside or on both sides maintained their transmission patterns throughout the course of the experiment (Fig. $2 \mathrm{D}$ and F). Since paper mulch generally decomposes during the cropping season, it was expected that the optical properties of the paper mulch would change over time.

Spectroradiometry: Reflection of light. The quantity of light reflected off the white upper surface of the coextruded white/black polyethylene decreased as the wavelength increased (Fig. 3A). The mean values for light reflection within the 400-1100 nm range was $45 \%$. Other researchers have found similar, but slightly higher results. Kluitenberg et al. (1991) found that a highly reflective, white/black polyethylene mulch reflected $50 \%$ of the incoming light within the 400-1100 nm range. The coextruded white/black polyethylene mulch used in the present experiment was not a pure, bright, white but was grayish due to the black color underneath. This appearance of the mulch may have reduced reflection. Reflected light may have been further reduced by a fine coating of organic soil that collected on the surface of the mulch.
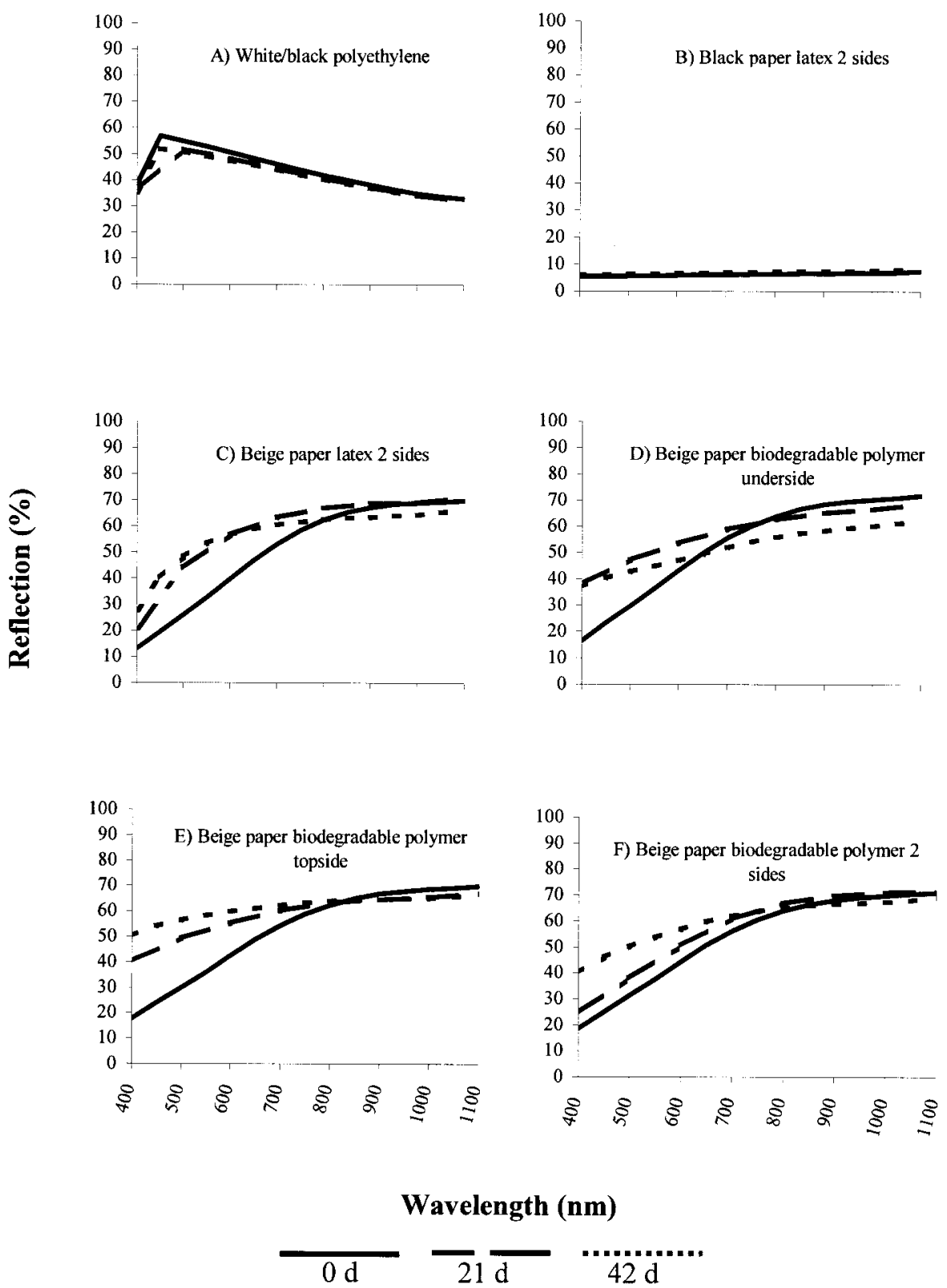

Fig. 3. Percentage of light reflection by polyethylene and paper mulches, after 0,21 , and $42 \mathrm{~d}$ in the field.

Light reflection from the black paper mulch coated with latex was minimal $(6 \%$ in $P A R$ range to $9 \%$ in the near IR range) and remained stable over time (Fig. 3B). The beige paper mulch coated with latex reflected an average of $33 \%$ of the light in the PAR range at the beginning of the experiment, and an average of $50 \%$ after $42 \mathrm{~d}$ (Fig. 3C). The percentage of light reflected by papers coated with polymer on the topside and on both sides increased over time (Fig. $3 \mathrm{E}$ and F). Beige paper coated with biodegradable polymer on the underside reflected more light at $21 \mathrm{~d}$ than at $42 \mathrm{~d}$ (Fig. 3D). A possible explanation for this is that while the surface of this paper was being exposed to the bleaching action of the sun, it simultaneously was becoming ingrained with dirt. Indeed, dirt stuck to the exposed paper surface.

Spectroradiometry: Absorption of light. Absorption levels of the coextruded white/ black polyethylene were stable throughout the observation period and varied from $40 \%$ in the
PAR range to $60 \%$ in the IR range (Fig. 4A). The black paper coated with latex absorbed more than $90 \%$ of the light in all of the wavelengths studied (Fig. 4B). This mulch exhibited no change in absorption over the time. In general, light absorption of the beige paper decreased with longer wavelengths as the reflection and transmission values increased (Fig. 4C-F).

Weed growth. A minimal number of monocotyledonous weeds were observed and no significant $(P<0.05)$ differences were noted among treatments in 1997 (Table 2). Although, a few dicotyledonous weeds (four and one) were visible under the black paper mulch at the first and second sampling, no weeds were visible at subsequent sampling dates. Dicotyledonous weeds were found under the beige paper treated with latex and white/black polyethylene at each sampling date. These weeds did not develop beyond the cotyledonary or two-leaf stage; their dry 
weights were always $<0.1$ g compared with $0.11 \mathrm{~g}(7 \mathrm{~d})$ and $13.3 \mathrm{~g}(35 \mathrm{~d})$ for the nonweeded control (data not shown).

Temperature, moisture, and light are the three main factors affecting seed germination (Leblanc et al., 1998). The low level of light transmitted by the beige paper mulches $(0 \%$ to $20 \%$ of the light transmitted in the $P A R$ range) could explain the poor weed emergence and growth. The lettuce architecture also influenced weed growth. The wrapper leaves of the lettuce, which completely covered the planting holes by the end of the experiment, reduced light to understory plants, and consequently prevented weed growth. The experimental field used in 1998, which has been under turf production for a number of years, had minimal weed growth and no significant differences among the treatments were detected, including the nonweeded control (data not shown).

In the nutsedge experiment, the population of nutsedge in the nonweeded control ranged from 1.3 to 23 shoots $/ \mathrm{m}^{2}$ at 14 and $42 \mathrm{~d}$, respectively (data not shown). The dry weights of the nutsedge and other weeds were significantly greater in the nonweeded control than in all other treatments except for the paper mulch coated on the topside (Table 3 ).

A single, etiolated nutsedge plant (dry weight $<0.1 \mathrm{~g}$ ) was discovered under the white/ black polyethylene upon removal of the mulch. Growth of other weeds under this mulch was also minimal. The black paper mulch coated with latex completely prevented the growth of weeds. Weeds started to force their way through the beige paper coated with a biodegradable polymer on the top $42 \mathrm{~d}$ after placement. The paper underside tended to degrade with time leaving only the translucent coating on top. The weeds then grew freely as reflected by the dry weights, which were heavier (significantly so in the case of other weeds) than those in the other mulch treatments.

The other beige papers used transmitted $<20 \%$ of the light in the PAR range after $42 \mathrm{~d}$ (Fig. 2). The average dry weight of yellow nutsedge found under the beige mulches (excluding the beige paper mulch coated on the topside) was calculated to be $1.2 \mathrm{~g} \cdot \mathrm{m}^{-2}$ (Table 3). The dry weight of the other weeds was lowest in the paper treated with polymer on both sides. These papers may be analogous in terms of $P A R$ transmission to an infrared transmitting (IRT) plastic mulch used by Majek and Neary (1991). They reported average nutsedge shoot weights of $16.6 \mathrm{~g} \cdot \mathrm{m}^{-2}(60$ shoots/ $\mathrm{m}^{2}$ ) under IRT mulch $117 \mathrm{~d}$ after the mulch was laid and, as in our experiment, yellow nutsedge shoots under the mulch were etiolated.

This experiment clearly shows that paper mulches can maintain their integrity and be successfully used to control weeds for the duration of a fast growing crop such as lettuce. All the mulches (except the beige paper coated with a biodegradable polymer on the topside) controlled weeds, including yellow nutsedge, for $42 \mathrm{~d}$. When working with paper mulches the protective coating, and not the paper itself, should come in direct contact with the soil. Indeed, mulch treated with coating on the
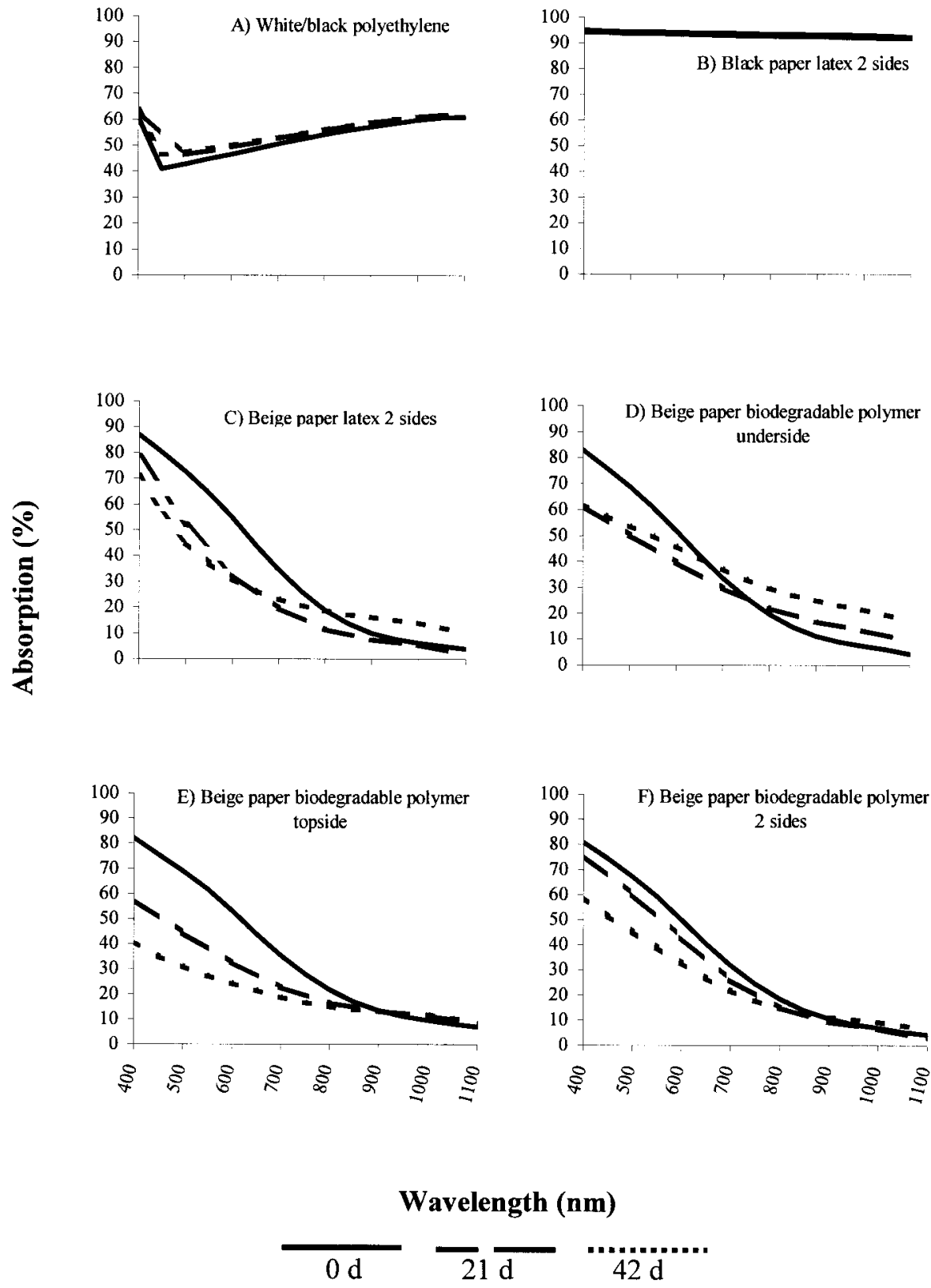

Fig. 4. Percentage of light absorbed by polyethylene and paper mulches, after 0,21 , and $42 \mathrm{~d}$ in the field.

Table 2. Effect of mulch type on number of monocotyledonous and dicotyledonous weeds ${ }^{\mathrm{z}}$ in a randomized $25 \times 25-\mathrm{cm}$ area, $7,14,21,28$, and $35 \mathrm{~d}$ after transplanting lettuce in 1997. Values are means of four blocks.

\begin{tabular}{|c|c|c|c|c|c|c|c|c|c|c|}
\hline \multirow[b]{2}{*}{ Time after transplanting (d) } & \multicolumn{5}{|c|}{ Monocotyledonous weeds } & \multicolumn{5}{|c|}{ Dicotyledonous weeds } \\
\hline & 7 & 14 & 21 & 28 & 35 & 7 & 14 & 21 & 28 & 35 \\
\hline White/black polyethylene & 0.0 & 0.0 & 0.5 & 0.3 & 0.3 & $15 \mathrm{a}^{\mathrm{z}}$ & $10 \mathrm{ab}$ & $3 \mathrm{~b}$ & $7 \mathrm{ab}$ & $2 \mathrm{bc}$ \\
\hline Black paper latex double sided & 0.0 & 0.0 & 0.0 & 0.0 & 0.0 & $4 \mathrm{~b}$ & $1 \mathrm{~b}$ & $0 \mathrm{~b}$ & $0 \mathrm{~b}$ & $0 \mathrm{c}$ \\
\hline Beige paper latex double sided & 0.3 & 0.8 & 0.0 & 0.5 & 0.0 & $15 \mathrm{a}$ & $10 \mathrm{ab}$ & $10 \mathrm{~b}$ & $9 \mathrm{ab}$ & $7 \mathrm{ab}$ \\
\hline Nonweeded control & 0.0 & 0.3 & 0.0 & 0.3 & 0.3 & $10 \mathrm{ab}$ & $20 \mathrm{a}$ & $19 a$ & $16 \mathrm{a}$ & $12 \mathrm{a}$ \\
\hline
\end{tabular}

${ }^{2}$ Mean separation within columns by Student-Newman-Keuls (SNK) test at $P<0.05$.

topside only degraded faster than all other mulches, allowing light to pass through it resulting in weed growth. After a rainy period, the unprotected surface of the paper coated only on the underside remained wet longer than the other papers. Although not a problem in this experiment, this moist environment might encourage disease development. Paper or coextruded white/black mulches may be suitable alternatives to the manual and mechanical weeding that is currently employed in lettuce. However, an economic study should be conducted to compare the costs use of using mulches with the existing methods of weed control. Decomposition measurements should also be under taken over a number of years to assess the durability of paper mulches under a range of climatic conditions. 
Table 3. Effect of mulch type on the dry weight $(\mathrm{g})$ of yellow nutsedge and other weeds found in $1 \times 0.76-\mathrm{m}$ size experimental plots under the mulches, $61 \mathrm{~d}$ after the start of the 1998 experiment.

\begin{tabular}{llcc}
\hline & & \multicolumn{2}{c}{ Dry wt $(\mathrm{g})^{\mathrm{z}}$} \\
\cline { 3 - 4 } Material & \multicolumn{1}{c}{ Color/Type } & Yellow nutsedge & Other weeds \\
\hline Polyethylene & White/black & $0.1 \mathrm{c}^{\mathrm{y}}$ & $0.1 \mathrm{~d}$ \\
Paper & Black, latex double-sided & $0.0 \mathrm{c}$ & $0.0 \mathrm{~d}$ \\
Paper & Beige, latex double-sided & $1.1 \mathrm{bc}$ & $11.3 \mathrm{c}$ \\
Paper & Beige, biodegradable polymer underside & $0.5 \mathrm{bc}$ & $4.9 \mathrm{~cd}$ \\
Paper & Beige, biodegradable polymer topside & $5.6 \mathrm{ab}$ & $150.1 \mathrm{~b}$ \\
Paper & Beige, biodegradable polymer double-sided & $1.2 \mathrm{bc}$ & $2.9 \mathrm{~cd}$ \\
Nonweeded control & & $11.9 \mathrm{a}$ & $214.3 \mathrm{a}$ \\
\hline
\end{tabular}

${ }^{2}$ Data were square-root transformed prior to analysis of variance. Means for four blocks.

${ }^{y}$ Mean separation within columns by Student-Newman-Keuls (SNK) test at $P<0.05$.

${ }^{\mathrm{x}}$ Mulch was torn by the weeds $42 \mathrm{~d}$ after installation.

\section{Literature Cited}

Alex, J.F. 1992. Ontario weeds. Ontario Ministry of Agr. and Food. Publ. 505, Agdex 640. Toronto.

Anderson, D.F., M.A. Garisto, J.C. Bourrut, M.W. Schonbeck, R. Jaye, A. Wurzberger, and R. DeGregorio. 1995. Evaluation of paper mulch made from recycled materials as an alternative to plastic film mulch for vegetables. J. Sustainable Agr. 7:39-61.

Clarkson, V.A. 1960. Effect of black polyethylene mulch on soil and microclimate temperature and
Loy, B. and O. Wells. 1990. Effect of IRT mulches on soil temperature, early vegetative development in muskmelon, and weed growth. Proc. Natl. Agr. Plastic Congr. 22:19-27.

Majek, B.A. and P.E. Neary. 1991. Selective wavelength transmitting mulch for yellow nutsedge control. Brighton Crop Protection ConferenceWeeds. Surrey: BCPC Registered Office 1:263268

Naegely, S. and C. Greenleaf. 1999. Get ready. Amer. Veg. Grower Feb. 1999. p. 10-11.

Roberts, H.A., R.T. Hewson, and M.E. Ricketts. 1977. Weed competition in drilled summer lettuce. Hort. Res. 17:39-45.

Rosenberg, N.J., B.L. Blad, and S.B. Verma. 1983. Microclimate: The biological environment. 2nd ed. Wiley, New York.

Schonbeck, M.W. and G.K. Evanylo. 1998. Effects of mulches on soil properties and tomato production. I. Soil temperature, soil moisture and marketable yield. J. Sustainable Agr. 13:55-81.

Shrefler, J.W., W.M. Stall, and J.A. Dusky. 1996. Spiny amaranth (Amaranthus spinosus L.), a serious competitor to crisphead lettuce (Lactuca sativa L.). HortScience 31:347-348.

Tumbleson, M.E. and T. Kommedahl. 1961. Reproductive potential of Cyperus esculentus by tubers. Weeds 9:646-653. 